\title{
Soft Soldering Gold Coated Surfaces
}

\author{
TECHNIQUES FOR MAKING RELIABLE JOINTS
}

\section{P. A. Ainsworth}

Tin Research Institute, Perivale, England

\begin{abstract}
Gold plated components are frequently required to be assembled by soft soldering, and it is important that the joints should be sound. This article reviews the factors influencing the mechanical properties of tin-lead soldered joints between gold surfaces and describes practical methods for ensuring their reliability in quantity production.
\end{abstract}

Gold possesses a unique combination of properties of particular value in the construction and operation of electrical and electronic equipment. These properties include high resistance to tarnish and corrosion, low electrical resistivity and contact resistance, ease of thermal compression and ultrasonic bonding and, particularly in the case of certain gold-based alloys, high resistance to mechanical wear.

Most efficient use is made of these properties by employing gold, usually in the electroplated form, either as an intermediate layer in certain microelectronic devices, or as a finish on such components as connectors, terminations, and printed circuits. Components coated in this way are frequently required to be assembled by soft soldering, but although gold is very easily wetted by molten tin-lead alloys using non-corrosive rosin fluxes $(1,2,3,4)$ the joints so formed are often found to be mechanically weak,

Published information on the reliability of soldered joints on gold is confusing, apparently contradictory results having been reported by different authors, and the purpose of this article is therefore briefly to review the factors influencing joint properties and the conditions under which reliable joints may be made.

\section{Factors Affecting Joint Properties}

Gold dissolves extremely rapidly in molten tin-lead solders, values quoted in the literature for the rate of solution in 60 per cent tin- 40 per cent lead at $250^{\circ} \mathrm{C}$, for example, varying from $4 \mu \mathrm{m} / \mathrm{s}$ for pure gold wire (5) to $10 \mu \mathrm{m} / \mathrm{s}$ for an electroplated gold of unspecified composition (6). The solid solubility of gold in both tin and lead is, however, very small, and the addition of even less than 0.5 per cent gold to tin-lead solders results in the appearance of the intermetallic compound $\mathrm{AuSn}_{4}$ in the solid alloy. This compound is hard and brittle and has a strong tendency to grow from the melt in the form of coarse plates or needles. Consequently, when present in sufficient quantities the compound embrittles the solder, the ductility and impact strength of a tin-40 per cent lead-gold alloy, for example, falling rapidly when the gold content exceeds 4 to 5 per cent and reaching a very low level with 8 to 10 per cent gold $(6,7)$.

Clearly, if rapid solution of the gold during soldering causes the gold content of the solder to rise above about 5 per cent the joint itself will be very brittle. Moreover, a continuous layer of $\mathrm{AuSn}_{4}$ forms during soldering at the solder-gold interface and when this increases in thickness beyond a certain very low value the bond between the compound and the gold substrate is considerably weakened, thus further reducing joint strength.

It will be apparent from the foregoing that the properties of soldered joints on gold-plated surfaces are likely to be affected by a number of factors including the time and temperature of soldering and the characteristics of the gold plate. These factors have been examined by a number of workers, one of the most comprehensive investigations being that by Harding and Pressly (3), some of whose results are summarised in the graph on page 49 . In general, it has been found that soldered joints on metals which are themselves wetted by molten solder, and which have been freshly plated with either pure or alloyed golds up to about $1 \frac{1}{2} \mu \mathrm{m}$ thick, have mechanical properties similar to those of joints made directly to the bare substrate. The gold completely dissolves in the solder enabling the solder to wet and bond to the substrate and the amount of $\mathrm{AuSn}_{4}$ which precipitates in the bulk of the solder is insufficient to impair joint properties.

As the plating thickness is increased above about $1 \frac{1}{2} \mu \mathrm{m}$ the gold is not completely dissolved during most soldering operations and the increasing amount of intermetallic compound that is formed, particularly at the interface, causes a progressive fall in shear strength and an even more rapid fall in resistance to 


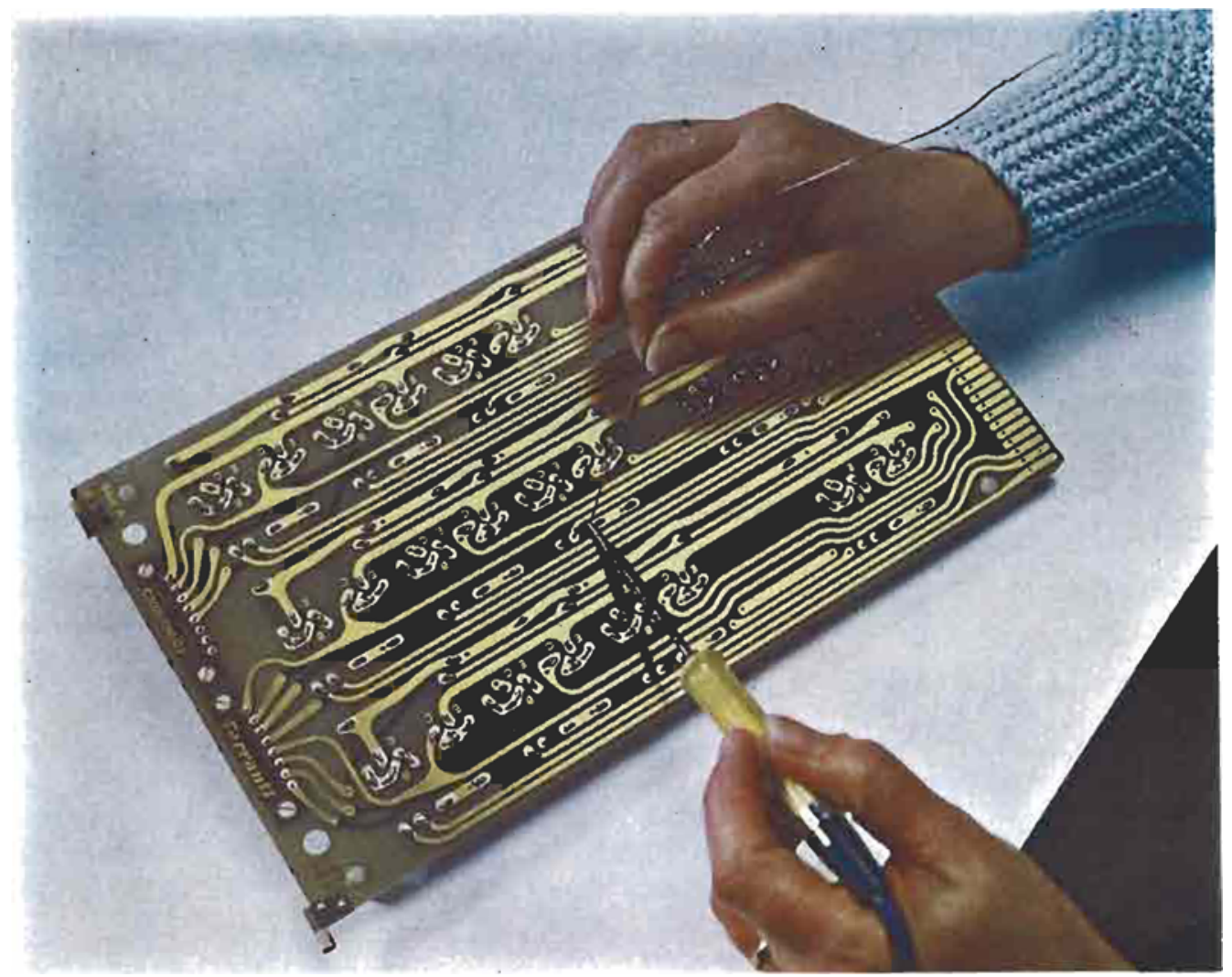

Gold plating over 65 per cent tin-35 per cent nickel alloy plating provides excellent solderability and resistance to corrosion for such applications as computers where long-term reliability in service is essential. A multilayer printed circuit hoard plated with gold over tin-nickel is being hand soldered with a 60 per cent tin -40 per cent lead alloy at Ferranti Digital Systems Division

impact and fatigue stresses. Joint weakening is particularly marked with alloy gold deposits greater than about $1 \frac{1}{2} \mu \mathrm{m}$ thick containing small amounts of nickel, cobalt, or silver. It is not clear whether this is due to a dewetting effect, as suggested by Harding and Pressly, or to the combined effects of the high internal stress levels common in such deposits and a stress arising from a volume change associated with the formation of the intermetallic compound.

Increasing either the temperature or the time of soldering increases the amount of intermetallic com-

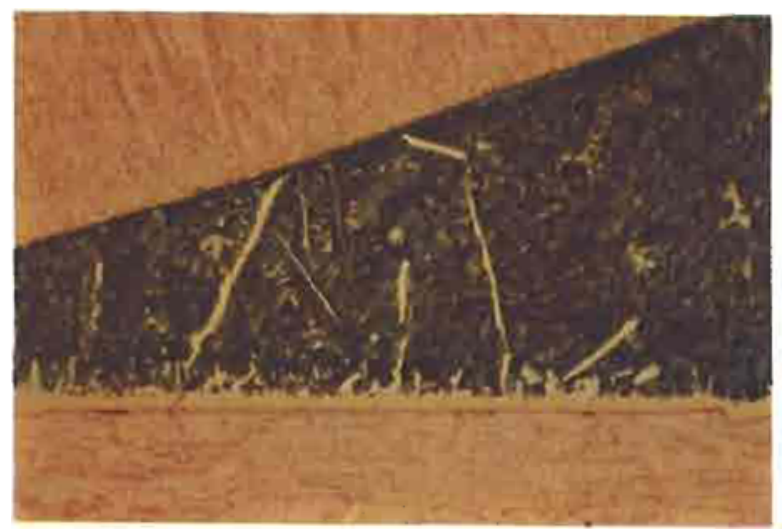

pound formed, thus reducing joint strength. Harding and Pressly, and Ross and Lee (8) noted that with coatings of both pure and cobalt-alloyed gold greater than $1 \frac{1}{2} \mu \mathrm{m}$ thick soldered with 63 per cent tin-37 per cent lead, the deterioration of joint strength became much more severe when the soldering temperature exceeded $240^{\circ} \mathrm{C}$. Presumably this temperature effect is due mainly to the formation of a critical amount of intermetallic compound arising from the exponential rise with temperature of the rate of solution of gold, but the formation of some $\mathrm{AuSn}_{2}$ and an associated peritectic reaction at about $210^{\circ} \mathrm{C}(9,10)$ may also be contributory factors.

\footnotetext{
A photomicrograph showing the structure of a polished section through a typical joint, soldered with a 60 per cent tin -40 per cent lead alloy, on copper plated with $4 \mu \mathrm{m}$ gold. The light coloured intermetallic compound $\mathrm{AuSn}_{4}$ has formed both as a layer between the gold and the ductile, dark etching solder. and as ncedles growing into the solder. Because it is brittle the AuS $1_{4}$ reduces the ductility and impact strength of the joint
} 


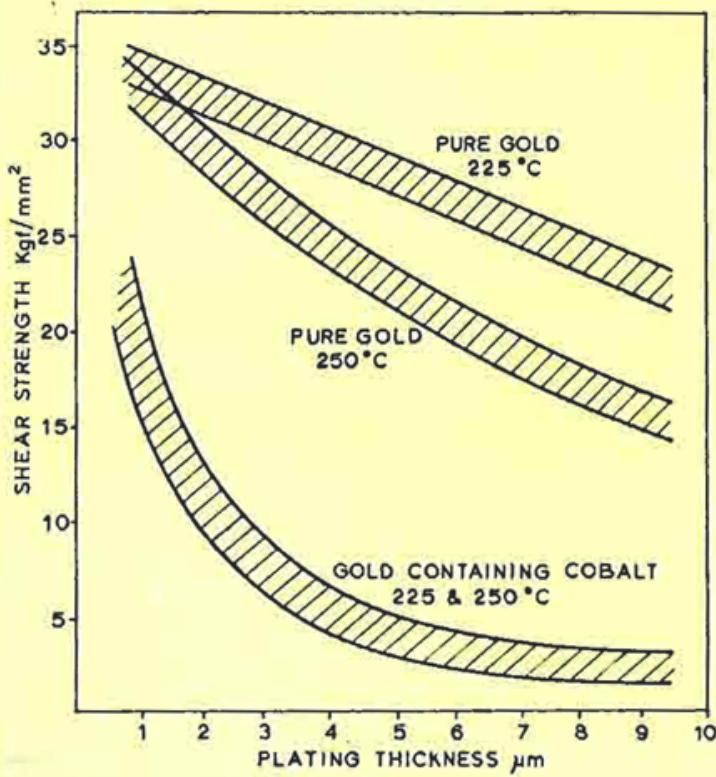

The effect of soldering time and temperature, and of plating thickness and composition, on the shear strength of lap joints between gold plated stripg soldered with 63 per cent tin-37 per cent lead were investigated by Harding \& Pressly (3). Some of their results have been replotted and form the broad curves shown here

Little information has been reported in the literature on the influence of solder compositions other than 60 per cent tin -40 per cent lead on joint embrittlement. No significant advantage appears to be gained by employing lead-tin solders with tin contents in the range 20 to 50 per cent since the influence of the necessarily higher soldering temperature on the rate of reaction between tin and gold offsets the effect of the lower tin concentration and there is, additionally, a greater possibility of forming brittle gold-lead compounds. Lower reaction rates are obtainable with lead-tin alloys containing only about 5 per cent tin, but these solders have inferior wetting properties and no information has been published on the mechanical properties of joints made with them on gold plated surfaces.

The rate of attack on gold is reduced by the addition of silver to a 60 per cent tin- 40 per cent lead solder, and even further reduced by the use of a tin-lead-cadmium alloy with a melting range of $186^{\circ}$ to $230^{\circ} \mathrm{C}$. However, again, no comparative data have been published on the mechanical properties of joints made with these alloys between gold plated surfaces. Joint embrittlement is greatly reduced by the use of certain lead-tin-indium (11) and lead-tin-indiumzinc (12) solders with lower melting points than 60 per cent tin- 40 per cent lead due, it appears, partly to lower soldering temperatures and partly to the preferential formation of $\mathrm{AuIn}_{2}$ at the interface, both these factors inhibiting the growth of $\mathrm{AuSn}_{4}$. However, as well as being very expensive these solders give joint strengths (13) considerably lower than those possible with 60 per cent tin- 40 per cent lead and they are rarely used in practice.

\section{Making Reliable Joints with Tin-lead Solder}

It emerges that the most obvious way to ensure mechanically reliable joints on both pure and alloyed gold surfaces is to use a plating thickness no greater than $1 \frac{1}{2} \mu \mathrm{m}$. It should be borne in mind, however, that under these conditions the gold acts as an entirely soluble coating and that the surface preparation of the substrate before gold plating must be adequate to permit wetting by the solder. Unfortunately this approach suffers from the disadvantage that the solderability of such thin gold coatings deteriorates quite rapidly during storage, particularly with copper and copper alloy substrates, presumably because of oxidation or corrosion of the surface basis metal through pores in the coating. The delay between plating and soldering must, therefore, be short. Thin coatings of pure gold over either silver or 65 per cent tin-35 per cent nickel $(14,15)$ plating provide notable exceptions to this principle, retaining their solderability with rosin-based fluxes over very long periods, probably because corrosion products from these substrates do not spread from the pores over the surface of the gold.

The conditions selected for making soldered joints on surfaces plated with rather thicker gold coatings, which retain their solderability well, will depend on joint configuration, the soldering technique employed and the degree of joint strength required. It is feasible, for example, to produce reliable joints on gold plated printed circuit board assemblies by direct wave or dip soldering provided one chooses a plating thickness sufficient to maintain solderability during storage and a time of contact with the molten solder at, say, $250^{\circ} \mathrm{C}$ sufficient to dissolve all the gold off the printed circuit pads and the component terminations. The quality of the joints is not impaired by gold concentrations in the solder bath of up to about 1 per cent.

This approach may not always be satisfactory because of adverse effects of temperature on the electronic components and on the printed circuit board, and it will certainly not be satisfactory when hand soldering due to an excessive rise in the gold content of the limited amount of solder in the joint. Joints with a reasonable resistance to static stress may be made between components plated with thicker pure gold coatings using either hand or automatic soldering methods by employing a soldering temperature less than $240^{\circ} \mathrm{C}$ and the shortest possible 
soldering time. However, the resistance of the resulting joints to impact and fatigue stresses is open to doubt and the rigid control required on the soldering process is not always practicable under production conditions.

Mechanically reliable joints may be obtained on surfaces plated with thick gold deposits after treating the area to be soldered by either of the processes commonly referred to as "washing off" and "wicking off". The essential features of both these processes are the solution of the gold in molten tin-lead solder followed by the removal of most of the solder to leave a thin coating of a tin-lead-gold alloy, with a low gold content, on the surface of the basis metal to which the joint may be made using fresh solder. With many components, such as connector pins and termination wires, simultaneous washing off and pretinning is conveniently carried out by dipping in either a static bath or a wave of molten tin-lead alloy. Again it should be remembered that the metal surface under the gold plating must have been adequately prepared to ensure wetting, and a layer of copper under the gold on such alloys as nickel-iron and cobalt-nickel-iron, which are not easily wetted using rosin fluxes, is an advantage. The gold content of the dipping bath may be allowed to rise to 1 per cent or so without impairing either the solderability of the tinned wire or the quality of the joint. When a dipping technique is inconvenient the solder may be applied and then drawn or "wicked" off with a soldering iron. The surface of the soldering iron bit used for this purpose will quickly become contaminated with gold and the use of another, uncontaminated, bit for the final soldering operation is preferred.

\section{Conclusions}

Reliable tin-lead soldered joints between gold plated surfaces may be obtained by effecting a bond between the solder and the basis metal and ensuring that the gold content of the solder in the joint is very low. This can be achieved by the use of freshly plated pure or alloyed gold no more than $I_{2}^{\frac{1}{2}} \mu \mathrm{m}$ thick or, in the case of thicker coatings, by simultaneous removal of the gold and pretinning over the area to be soldered. Because the solderability of gold plating, no more than $\mathrm{I} \frac{1}{2} \mu \mathrm{m}$ thick on many substrates, including copper, deteriorates rapidly during storage due to porosity in the coating, the development of a technique for producing thin, pore-free, gold plating, would constitute a great advance (16).

Fairly high joint shear strengths may be obtained by soldering directly to gold plating more than $\mathrm{I}_{2} \frac{1}{2} \mathrm{~m}$ thick using a very low soldering temperature and a short soldering time, but the impact and fatigue strengths of such joints are open to doubt. Joints made to most bright alloyed gold plating greater than $I_{2}^{1} \mu \mathrm{m}$ thick have very poor mechanical properties.

The procedures outlined above for making completely reliable joints on thick gold deposits using the common tin-lead solders are both inconvenient and costly in terms of time and there is, therefore, a need for an inexpensive solder which does not give rise to a brittle interface when it reacts with gold. Although interfacial embrittlement can be prevented by the use of certain indium-bearing alloys, these solders have the disadvantage that they are very expensive and, moreover, the strengths of joints made with them are low. Less expensive tinlead-based alloys containing either silver or cadmium are claimed to dissolve gold more slowly and hence to give less growth of intermetallic compound than plain tin-lead alloys. However, because of the lack of information on the mechanical properties of joints made with these solders, further work would seem to be desirable to confirm that embrittlement does not occur at the solder-intermetallic compound interface.

It is evident that the greatest embrittlement problem arises when soldering is carried out on bright, hard, alloyed gold deposits. In view of the importance of such coatings in conferring wear resistance to such components as connectors, more detailed investigation also appears to be necessary on the influence of both the chemical and physical properties of the gold plating on embrittlement.

\section{Acknowledgement}

The author is indebted to the International Tin Research Council for permission to publish this article.

\section{References}

1 A. Korbelak and R. Duva, Am. Electroplaters Soc., 48th Ann. Tech. Proc., 1961, 142

2 J. M. Thompson and L. K. Bjelland, ibid., 182

3 W. B. Harding and H. B. Pressly, Am. Electroplaters Soc. 50th Ann. Tech. Proc., 1963, 90

4 C. J. Thwaites, Trans. Inst. Metal Finish., 1965, 43, 143

5 W. G. Bader, Welding f., 1969, 48, 551S

6 M. H. Bester, Proc. Inter/Nepcon 1968, Brighton, Kiver Publications Inc., Chicago, 211

7 F. G. Foster, A.S.T.M. Spec. Tech. Pub. 319, 1962, 13

8 W. M. Ross and E. A. R. Lee, Proc. Inter/Nepcon, 1968, Brighton, Kiver Publications Inc., Chicago, 206

9 A. Prince, $\mathcal{F}$. Less-Common Metals, 1967, 12, 107

10 M. M. Karnowsky and A. Rosenzweig, Trans. Metall. Soc. A.I.M.E., 1968, 242, 2257

$11 \mathrm{~J} . \mathrm{D}$. Braun and T. B. Rhinehammer, A.S.M. Trans. Q., 1963, 56, 870

12 J. D. Braun, ibid., 1964, 57, 568

13 R. Weil, R. P. Diehl and E. C. Rinker, Plating, 1965, 52,1142

14 A. W. Castillero, Metal Finish, 1964, 62, (2), 61

15 G. C. Wilson, Proc. Inst. Metal Finish., Printed Circuit Group, Ann. Symp,, Harrogate, Nov. 1970 (to be published in Trans. Inst. Metal Finish.)

16 H. S. Campbell, Gold Bull., 1971, 4, (1), 12 